\title{
Morfologias Urbanas e Espaços Públicos na Metrópole de Lisboa Uma Aproximação Instrumental e Metodológic no Quadro de uma Investigação
}

\author{
V. Matias Ferreira* \\ Alexandra Castro ** \\ João Seixas ${ }^{* * *}$ \\ Isabel Pato e Silva ${ }^{* * * *}$ \\ Elisabete Lopes ${ }^{* * * * *}$
}

\begin{abstract}
$\mathrm{R}$ central se desenvolve em torno dos espaços públicos e do protagonismo urbano. Apresenta-se um quadro instrumental e metodológico, que se encontra em fase experimental de aplicação. Uma das hipéteses de pesquisa, apoiada no respectivo trabalho de observação empírica, tende a ilustrar o eventual protagonismo da Metrópole de Lisboa através da manifestação ou emergência de factores conducentes a uma determinada qualidade social e urbana do espaço em observação. Partindo-se da hipótese que existem determinadas áreas emblemáticas das transformações sociais e territoriais e condicionantes da configuração metropolitana, procurou-se estruturar um quadro metodológico que facilitasse a utilização e articulação do material empírico resultante da análise de espaços públicos concretos da Metrópole de Lisboa, olhada através de diferentes lentes analíticas: a escala metropolitana, a escala urbana e a escala local. A matriz analítica centrada no espaço público enquanto base para o estudo do protagonismo urbano (nas perspectivas urbanística, política e sociocultural) assenta em quatro dimensões analíticas. Procura-se uma nova síntese do urbano na qual o espaço público é simultaneamente objecto de análise e vertente analítica privilegiada para a concretização dos planos analíticos que enquadram o estudo do protagonismo urbano em espaço público.
\end{abstract}

Palavras-Chave: morfologias urbanas; protagonismo urbano; espaços públicos; metrópole de Lisboa.

\section{Apresentação}

No contexto de diversas pesquisas inseridas num projecto de investigação em curso ${ }^{1}$, apresentase seguidamente um quadro instrumental e metodológico, que se encontra em fase experimental de aplicação empírica, construído em função de alguns dos objectivos daquela investigação. Por outro lado, certas dimensões mais determinantes do enquadramento analítico da referida investigação foram já, em certa medida, apresentados noutro momento (nesta mesma revista), através da publicação de um texto do coordenador desse projecto (V. Matias Ferreira, 2001). Daquele enquadramento, recorde-se duas das dimensões efectivamente analisadoras do objecto privilegiado das pesquisas a desenvolver, dimensões essas centradas nas morfologias urbanas e nos espaços públicos da Metrópole de Lisboa. Realmente, através do jogo articulado dessas dimensões analíticas, as pesquisas em curso pretendem vir a ilustrar graus e modos de afirmação qualitativa daquele território metropolitano, num contexto mais geral em que estará em causa discutir o que então designámos de protagonismo da Metrópole de Lisboa. Adiante apresentaremos, de modo sucinto, esse mesmo enquadramento analítico, a partir do

\footnotetext{
* Catedrático de Sociologia do ISCTE.Contacto: vitor.ferreira@iscte.pt

** Socióloga. Investigadora do Centro de Estudos Territoriais. Contacto: alexandra.i.castro@seg-social.pt

*** Departamento de Geografia Humana, Universidade Autónoma de Barcelona. Investigador do Cet. Contacto: jseixas@esoterica.pt

**** Geógrafa. Mestre em Planeamento Regional e Urbano. Consultora do Cet. Contacto: isamig@hotmail.com

***** Socióloga. Investigadora do CET. Contacto: maria.lopes@iscte.pt

Projecto de Investigação financiado pela Fundação para a Ciência e Tecnologia (comparticipado pelo fundo comunitário europeu FEDER) intitulado "Património Urbano, Espaço Público e Protagonismo das Cidades. As Metrópoles de Lisboa e do Porto no Dealbar do Século XXI".
} 
qual será então possível partir para o quadro instrumental e metodológico da referida aplicação empírica. Antes, porém, é necessário sinalizar o "território" aqui em debate, avançando então para algumas das condições do que, do nosso ponto de vista, parece vir a configurar o que designamos de Metrópole de Lisboa.

\section{A Metrópole de Lisboa no Contexto do País}

Uma das hipóteses centrais de investigação que tem acompanhado, desde o início, o desenrolar das pesquisas a que este texto se reporta, tem a ver com uma discussão aprofundada sobre a condição económica, social, cultural e obviamente territorial do que consideramos poder vir a configurar a institucionalização da Metrópole de Lisboa. Sabemos que é uma hipótese teórica e empiricamente polémica, sobretudo porque procura romper e demarcar-se, em termos analíticos e operativos, dessa entidade politicamente "híbrida" e tecnicamente inconsequente que dá pelo nome de "área metropolitana" de Lisboa, cujo estatuto institucional não parece ter, portanto, correspondência pertinente em relação a qualquer uma das referidas dimensões analíticas de caracterização daquele mesmo território metropolitano. De resto, basta constatar a "fluidez" das diversas demarcações territoriais, nomeadamente ao nível regional, por razões de mera oportunidade económica e política ${ }^{2}$, para se entender a relativa arbitrariedade do que está em jogo. E muito embora o presente texto tenha objectivos mais de ordem instrumental e metodológica, não parece possível deixar de assinalar alguns dos argumentos que ajudam a desenvolver a referida hipótese de investigação, sendo certo também que já noutros momentos nos confrontámos com esse desafio (cfr., nomeadamente, V. Matias Ferreira et. al., 1997).

Em todo o caso, a presente hipótese de investigação não se apoia exclusivamente em factores "internos", digamos mais propriamente específicos desse mesmo espaço metropolitano, muito embora eles tendam a assumir um peso político, económico e social suficientemente determinante para justificar, em grande medida, aquela particular configuração metropolitana. Mas haverá também, certamente, fortes razões que decorrem das actuais assimetrias territoriais e das correspondentes polarizações sociais do próprio continente português, num diagnóstico praticamente consensual entre os diversos analistas. Tais assimetrias e polarizações configuram um quadro territorial bastante contraditório, socialmente desigual e politicamente iníquo, em que, por vezes, os próprios "sinais" de mudança apresentam, paradoxalmente, uma inércia pesada, contrariando aqueles mesmos processos de mudança! Razão para que se procure equacionar aquele quadro territorial, como diversos autores defendem, numa postura organizacional diferente, com um distinto ordenamento urbano e potenciando, assim, entre outras consequências, sinergias entre cidades e aglomerados urbanos - através de redes de cidades, por exemplo - o que poderia vir a permitir um efectivo reordenamento urbano e territorial, nomeadamente ao nível do território da península ibérica ${ }^{3}$.

Uma tal mudança deverá implicar, certamente, a necessidade de intervenções estratégicas em diversas áreas "urbanizadas" e em determinados espaços urbanos, procurando criar, assim, "massa crítica" territorial para um novo ordenamento socioespacial do continente. Realmente, é também globalmente reconhecida a importância decisiva que as cidades têm vindo a assumir no actual contexto de acentuada globalização do capitalismo. Entre outras razões, parece importante destacar que aquela mesma globalização, exactamente porque se projecta num contexto transnacional - questionando, profundamente, os limites "nacionais" da economia e da sociedade acaba por colocar os espaços regionais, com forte componente urbana e metropolitana, como os lugares estratégicos de afirmação e de competitividade, mas também de cooperação no referido contexto global.

Uma tal constatação foi explorada e de algum modo debatida em estudo anteriormente citado (op. cit., 1997), o que nos permite avançar, assim, para

\footnotetext{
${ }^{2}$ Um dos factos mais recentes tem a ver com o "emagrecimento" da dita região de Lisboa e Vale do Tejo, de modo a que alguns dos municípios, até então nela incluídos, pudessem continuar a candidatar-se aos famigerados fundos estruturais de apoio financeiro da União Europeia, uma vez que a referida região, com os limites territoriais anteriores, já não estaria dentro dos critérios de apoio da U.E.!

3 Já com este texto praticamente finalizado, soubemos da existência de um estudo de João Ferrão (editado pela DGOTDU) sobre as regiões metropolitanas no quadro da Península Ibérica, que, em momento posterior, certamente poderá vir a permitir aprofundar o posicionamento aqui apresentado.
} 
outro tipo de observações complementares às conclusões então apresentadas. Realmente, a partir do Plano Nacional de Desenvolvimento Económico e Social (PNDES), 2000-2006 (MEPAT, 1999, 54), podemos reter, desde já, duas proposições importantes: antes de mais, a necessidade do "reforço das áreas (ou futuras regiões) metropolitanas de Lisboa e Porto", uma vez que constituem "as aglomerações melhor colocadas para protagonizar papéis de intermediação do país com o exterior e assegurar a sua inserção nas dinâmicas da economia europeia e mundial". Com efeito, ainda segundo aquele Plano, "são estes os centros nacionais com maior capacidade de atracção e de fixação de fluxos, de iniciativas e de recursos indispensáveis ao desenvolvimento". Em complemento com a proposição anterior, reconhece-se a urgência em reorganizar aqueles espaços metropolitanos, "por forma a reduzir a expressão dos fenómenos de suburbanização, com particular destaque na área metropolitana de Lisboa, procurando caminhar para a consolidação de estruturas multipolares".

Uma tal argumentação, que já aparece desenvolvida num texto anterior de Félix Ribeiro (1998), é então explicitada por este autor em termos que nos parecem de extrema importância, vindo ao encontro, inclusivamente, da hipótese central aqui em discussão. Com efeito, aquele autor admite que em relação à reorganização daqueles espaços metropolitanos, seria de "ponderar a vantagem de operacionalizar as entidades 'Grande Lisboa' e 'Grande Porto', reconfigurando-as por forma a envolver concelhos das duas margens dos rios Tejo e Douro, permitindo com essa 'recentragem' sobre os rios, deixar espaço de afirmação a cidades médias mais distantes, mas localizadas nas respectivas áreas metropolitanas" (itálicos nossos). Esta última proposta, determinante como sabemos do ponto de vista territorial, abre sem dúvida para a referida hipótese que avançámos no início, sobre a constituição efectiva de duas Metrópoles, Lisboa e Porto, o que, no caso de Lisboa, parece ser já um passo importante para contrariar essa "invenção" política, territorialmente "híbrida", porque tenden- cialmente regional, que dá pelo nome de "área metropolitana"! Realmente, a "Grande Lisboa" é uma Cidade de Duas Margens, estruturada assim por um estuário que unifica essa mesma Cidade enquanto cidade metropolitana, conferindo-lhe portanto uma condição muito específica, territorialmente restrita e que consideramos designar, precisamente, por Metrópole de Lisboa ${ }^{4}$.

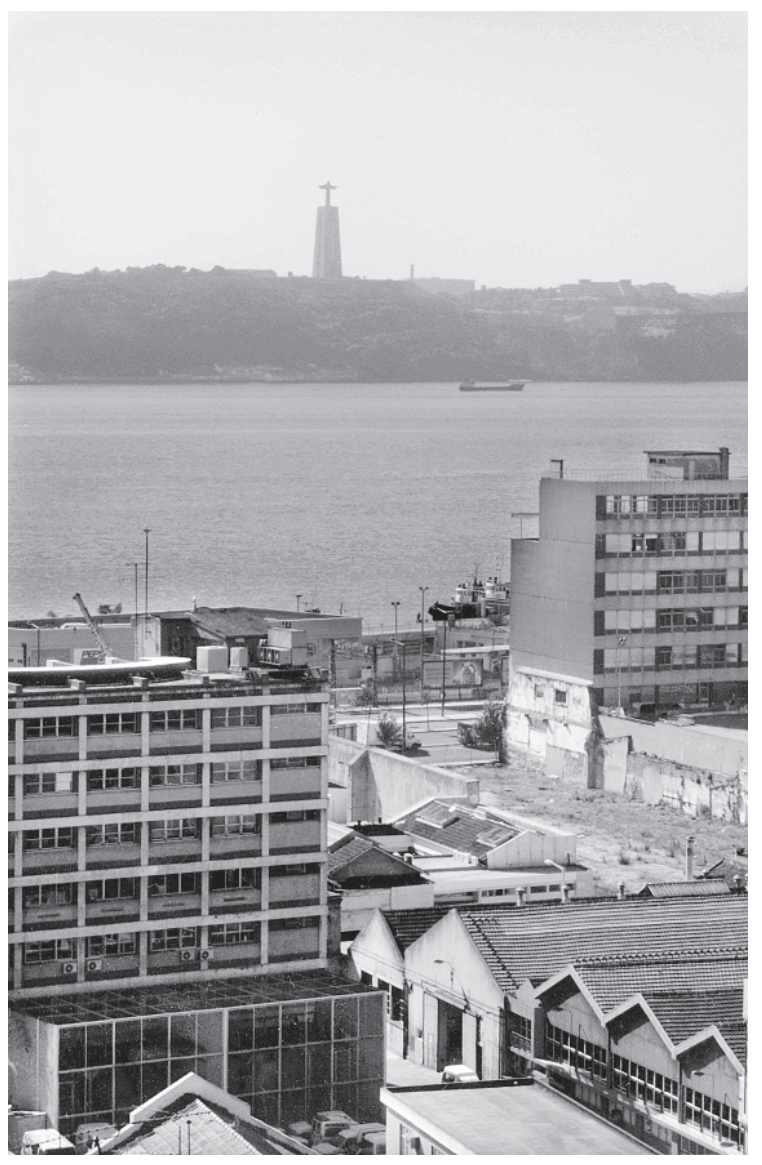

Foto de Alexandra Castro, Lisboa

Em tais condições, a assunção plena daquelas cidades metropolitanas, necessariamente também ao nível institucional, permitiria, assim, que as respectivas Metrópoles pudessem assumir-se com "massa crítica" territorial capaz de se projectarem como interlocutoras de um necessário reordenamento do país, mas também face ao exterior. Já no nosso estudo anteriormente citado (op. cit., 1997)

\footnotetext{
Sendo naturalmente difícil delimitar com precisão os contornos territoriais da Metrópole de Lisboa, no estudo anteriormente citado (op. cit., 1997), as pesquisas então efectuadas (polarização de fluxos, níveis de fixação da população activa, interacção das relações sociais, intercâmbio cultural, etc., entre os diversos municípios da dita "área metropolitana" de Lisboa) permitiram ilustrar uma muito significativa massa crítica territorial (no que isso pressupõe também, como sabemos, as respectivas dimensões económicas e sociais), polarizadora portanto de um território envolvendo, fundamentalmente, os municípios directa e imediatamente localizados a norte e a sul do referido estuário do Tejo. Aquela polarização, territorialmente desigual apesar de tudo, organiza-se contudo na base de uma estreita e profunda interacção socioespacial e económica, projectando assim a referida Metrópole de Lisboa.
} 
- em que procurámos fundamentar algumas das características comparativas da referida Metrópole de Lisboa, mas então no contexto de afirmação estratégica das suas frentes de água - considerámos estar perante uma das "teses" centrais para debater um distinto reordenamento territorial do continente, mais adequado, ao fim e ao cabo, ao mencionado protagonismo das cidades e, portanto, da própria Metrópole de Lisboa. Ou, de outro modo, um distinto modelo territorial para os espaços metropolitanos de Lisboa e do Porto, não deixaria de implicar, necessariamente, a urgência de um novo reordenamento do território do país, considerando, assim, as cidades e as "vilas urbanas" - eufemismo que pretende sublinhar que o que está em causa não são meras designações administrativas, mas ainda a questão da "massa crítica", neste caso avaliada em função da respectiva condição urbana e, nas situações referidas, ao nível também da condição metropolitana - como componentes fundamentais de projecção e de reorganização do respectivo território nacional.

Ao fim e ao cabo, Lisboa, enquanto tal, é um nome com vários conteúdos e distintas configurações, cujos limites (não exclusivamente de ordem física) são totalmente artificiais, deixando-a assim numa espécie de "anomia constitucional": por um lado, Lisboa entendida como "cidade", está condicionada pelos respectivos limites administrativos, concelhios, que como sabemos desde os anos 60 foram sendo sucessivamente superados; por outro, como "metrópole", está transfigurada numa entidade, politicamente híbrida como dissemos, intermédia (?) no quadro regional, sem suporte sociológico e urbanístico e que dá pelo nome de "Área Metropolitana" de Lisboa! Eis um dos grandes paradoxos institucionais, ao nível territorial do país, com que se tem procurado iludir a actual condição social e espacial de Lisboa. E, no entanto, o debate aprofundado sobre essa mesma condição ${ }^{5}$, será certamente crucial para se discutir, também, um outro ordenamento do território nacional.

\section{Morfologias Urbanas e Protagonismo da Metrópole}

Já em texto anteriormente citado, do coordenador da investigação aqui em causa, tivemos ocasião de discutir algumas das dimensões que organizam uma das abordagens analíticas centrais na referida investigação. Permitimo-nos retomar, assim, alguns dos elementos de fundamentação analítica explicitados no referido texto. Assinalámos então que uma das hipóteses das pesquisas em curso, apoiada, em grande medida, no respectivo trabalho de observação empírica, tenderia a ilustrar o eventual protagonismo da Metrópole de Lisboa através da manifestação ou emergência de factores conducentes a uma determinada qualidade social e urbana do espaço em observação. Em termos operativos, analíticos, uma tal hipótese, centrada numa das vertentes de ilustração dos processos e dos projectos de afirmação do mencionado protagonismo, orientou-se para a abordagem das morfologias urbanas dos espaços constitutivos e integrantes do território metropolitano de Lisboa. Sublinhe-se, entretanto, que com aquela designação "morfológica" estamos contemplando, simultaneamente, o que na linguagem urbanística configura a forma do tecido urbano, mas também o que, no quadro sociológico, se reporta à formação social urbana, no sentido de contemplar o correspondente sistema de relações sociais e culturais, bem como os respectivos quadros identitários da vida urbana (para um aprofundamento desta problemática, cfr. A. Firmino da Costa, 1999).

Tivemos então a oportunidade de estabelecer uma distinção fundamental entre espaços públicos urbanos (no plural, portanto) e espaço público da cidade (na sua singularidade identificadora da cidade), o que nos levou a admitir que esta mesma singularidade de identificação do território em causa assumia, assim, o papel de referente em relação ao que, em última instância, parece vir a constituir a própria condição pública da cidade. Não nos alongaremos, neste momento, sobre esse

\footnotetext{
${ }^{5}$ Um tal debate está longe de poder ficar confinado a uma mera questão dita "académica" - e, no entanto, esse será o primeiro (e definitivo?) comentário da generalidade dos "poderes instituídos"! Mas bastará ter em conta que o posicionamento proposto, entre outros desenlaces possíveis, joga directamente com a desconcentração territorial e com a descentralização política do país, para que se permita entender o alcance sociológico e urbanístico desse mesmo debate.
} 
mesmo debate, nomeadamente porque ele acabou por ter uma discussão mais aprofundada por um dos membros da equipe de investigação e que pode ser consultada neste mesmo número da revista cfr. Alexandra Castro, 2002. Em todo o caso, em relação àquela distinção tivemos ocasião de destacar uma temática-chave analisadora (numa formulação próxima da "sociologia institucional") das pesquisas aqui em discussão - reportamo-nos à referida análise das morfologias urbanas da cidade, na sua dupla condição social e espacial, como atrás sublinhámos. Um tal posicionamento metodológico teve, desde logo, um duplo objectivo, que decorreu das abordagens analíticas, estreitamente articuladas entre si, que aqui damos conta: num caso, o enfoque analítico procurou recensear e avaliar, através da inquirição das respectivas "formas urbanas", os espaços públicos (no plural) e o património urbano (tal como noutros momentos o fomos discutindo ${ }^{6}$ ) que, em conjunto, configuram e integram o espaço de observação; complementarmente, estará em causa - numa fase posterior da investigação - identificar e caracterizar a condição urbana (enquanto dinâmica qualitativa e prospectiva), bem como avaliar a projecção pública (no sentido, precisamente, da sua afirmação e do seu protagonismo) daquele mesmo território e, em última análise, da cidade-metrópole de Lisboa.

Em relação aquele enquadramento analítico, tivemos o cuidado de sublinhar, no entanto, que a análise das morfologias urbanas não constitui uma panaceia, nem ela capta, só por si, as dinâmicas de mudança social e espacial do respectivo território. Ou melhor, aquela análise morfológica deverá permitir uma melhor inquirição dessas dinâmicas, para além, portanto, das imagens aparentemente estáticas que, em cada momento, as "formas urbanas" possam apresentar. A este nível, portanto, uma análise estritamente urbanística (no sentido anteriormente referido) é manifestamente insuficiente, sendo mesmo duvidoso se constitui uma "etapa" de investigação! Em todo o caso, essas análises têm de ser ponderadas com outras abordagens, em especial com as que conjuguem as dinâmicas sociais e culturais de incidência local, com as propostas, projectos, planos, etc., de caracter sócio-político, para cada uma daquelas "formas urbanas". Ao fim e ao cabo, estamos perante "partes de um todo", ao nível local portanto, cuja compreensão mais profunda remete, necessariamente, para um referente mais global, neste caso, para a Cidade enquanto tal, isto é, no caso concreto, para a Metrópole de Lisboa. É esse mesmo desafio que está previsto, desde o início, para a fase final do presente projecto de investigação.

Aquela advertência sobre os riscos de leituras do espaço urbano e metropolitano demasiado "formalistas", é semelhante, ao fim e ao cabo, com os próprios riscos da herança demasiado pesada das perspectivas estritamente "funcionalistas" da cidade. E, no entanto, a análise funcional da cidade, enquanto tal, não tem que se esgotar naquelas mesmas finalidades funcionalistas, sem outras mediações, portanto, que não se reportem exclusivamente ao "bom funcionamento" da cidade. Por isso, se hoje podemos aceitar que "as formas urbanas já não seguem as funções da cidade" (Amendola, 2000), a análise das morfologias urbanas terá de se posicionar, também, em relação a determinados referentes exteriores a essas mesmas abordagens, que desse modo deixam de se constituir como estritamente morfológicas. Realmente, tal como veremos no ponto seguinte, a análise das morfologias urbanas - muito polarizada na própria pluralidade dos ditos espaços públicos - acabou por exigir uma discussão relativamente alargada sobre diversas tipologias analíticas, procurando construir assim instrumentos de observação que não se limitassem a uma estrita leitura "formal" dos espaços em causa.

Espaços públicos e património urbano constituíram, portanto, duas das temáticas centrais da presente investigação, tal como referimos atrás. Vimos então que em relação à primeira temática era possível assinalar uma dupla projecção de significados, na base precisamente de uma dupla valência - na pluralidade daqueles espaços urbanos, mas também na singularidade pública da respectiva cidade. Curiosamente, a temática do património urbano confronta-se, igualmente, com uma dupla significação: enquanto modalidade restritiva de entendimento do património exclusivamente nas suas dimensões históricas e culturais ou, inversamente, enquanto modalidade alargada, mas social e culturalmente significativa,

\footnotetext{
${ }^{6}$ Cfr. V. Matias Ferreira, 2000 e 2001. Tais reflexões, com um devido enquadramento e integradas num contexto analítico mais amplo, constituem parte de uma obra do autor a publicar em 2003.
} 
de um património que, pelo facto de assumir antes de mais um valor propriamente urbano, não deixa de contemplar também aquelas mesmas dimensões históricas e culturais. Duplicidade de significados que não introduzem, propriamente, ambiguidades analíticas, porque relativamente bem identificados, mas que produzem, sem dúvida, complexidades acrescidas!

Por isso dissemos (no texto anteriormente citado) que aquela dualidade de critérios sobre o património das cidades - homóloga, como vimos, à que é possível estabelecer em relação aos espaços públicos - está ainda hoje presente, embora com justificações políticas aparentemente distintas. Assim, no caso do património urbano parece possível distinguir, ainda que em termos um tanto esquemáticos, entre uma perspectiva que designámos noutro momento de "museográfica", de uma outra que tendo presente, naturalmente, a componente histórica e "monumental" do património, joga, sobretudo, com a dimensão identitária e cultural da cidade, que apropriadamente, como observámos então, Françoise Choay designou de historial (F. Choay, 1996). Significativamente, aquela visão parcelar e excepcional do património da cidade - entendido, assim, como conjunto de "peças" de um suposto "museu urbano", no qual a cidade ficaria encerrada - tem estado presente, na generalidade das situações, na origem da destruição de boa parte do respectivo património urbano, como então sublinhámos. Com efeito, aquele posicionamento, ao assumir-se como "excepcional" - e cuja excepcionalidade é ainda enfatizada na medida em que muitas vezes surge associada a processos de distinção e de classificação desse mesmo património "seleccionado" - tem vindo a caucionar, implícita ou explicitamente, consequências profundamente nefastas e irreversíveis (de destruição, ao fim e ao cabo), do "restante" património, considerado, assim, como "não excepcional" e nessa medida como passível de eliminação!

No quadro da investigação empírica que neste momento está aqui em causa, o desafio que se colocou, ao nível da análise das morfologias urbanas, foi o de procurar manter permanentemente em avaliação crítica a referida dualidade de critérios, tendo em conta que o actual contexto sócio-político é, ainda, particularmente "sensível" a uma tal ambiguidade processual. Ao fim e ao cabo, tendo em conta o posicionamento analítico que temos vindo a explicitar, património urbano e espaço público são assim como que o verso e o reverso de uma mesma problemática analítica, no caso centrada nas modalidades e nas condições de expressão do protagonismo urbano de cidades em processo de mudança económica, social e cultural. Nessa medida, o aprofundamento analítico daquelas duas temáticas - testando-se e validando-se, reciprocamente - não deixará de permitir uma avaliação crítica sobre as condições daquele mesmo protagonismo urbano e, deste modo, do próprio "projecto de cidade" que é suposto afirmar e projectar aquele mesmo protagonismo. Eis o que pode permitir uma melhor compreensão do texto que se segue, ao mesmo tempo que fica desde já anunciado para próxima publicitação das pesquisas em curso.

\section{Tipologias Urbanas e Análise Morfológica}

\section{Das Tipologias Urbanas}

O exercício de interpretar e projectar tipologicamente as complexas heterogeneidades de uma área metropolitana não é seguramente pacífico. Pretendendo-se assumir como abordagem fundamental de interpretação não só uma abordagem morfológica, mas também as componentes dinâmicas de evolução urbana, cujas forças têm resultado em dramáticas transformações metropolitanas nas últimas décadas, surge manifesta a necessidade de uma transversalidade no olhar. Numa lógica descritiva, existe uma vastíssimo legado analítico de conceptualizações que têm substantivado os fenómenos e os processos de metropolização. Desde a cidade compacta, nuclear e pendular, até aos fenómenos de rururbanização, as conceptualizações desenvolvidas e profusamente utilizadas até ao nível dos instrumentos de gestão territorial, denotam uma crescente dificuldade de interligação com uma realidade de comportamentos urbanos em uso alargado (Secchi, 1995), em territórios dispersos e sem confins, mas afinal plenos de confins nas suas visões e abordagens (Nel.lo, 2001), onde os grandes vectores de evolução urbana provêm de uma complexa interestruturação transversal de factores essencialmente sociais e económicos. 
Nesse sentido, sugere-se dois grandes focos de abordagem na construção de um enquadramento tipológico das realidades e fenómenos urbanos: a análise morfológica e a análise evolutiva (muito especialmente em termos das transformações mais recentes e mais marcantes).

A análise morfológica de uma metrópole (já muito aprofundada como acima referido) dirige-se a conceptualizações de centro-periferia, ou mesmo de multicentros e multiperiferias, reconhecíveis e assimiláveis por códigos morfológicos relativamente unívocos (Font, 1999), tais como centro consolidado, polígonos, crescimento suburbano, arco ribeirinho, cidade-jardim. No fundo, objectivações que se podem delimitar e quantificar sem dificuldades de maior, e sobre as quais se têm pautado quase toda as abordagens de investigação e acção. Surge neste sentido a classificação das diferentes 17 Unidades Territoriais do recente PROTAML ${ }^{7}$, constituindo estas a base do modelo territorial diagnosticado e sob as quais se projectam as opções estratégicas metropolitanas propostas, embora assumindo estas propostas componentes de caracterização mais dinâmicas;

A análise das transformações levanta uma série de novas visões de e para os territórios, por forças de análise dinâmica, interpenetrando-se com abordagens de fluxos e de processos como as de entendimento dos canais de comunicação e de mobilidade, e das próprias estratégias dos diferentes actores nos processos de desenvolvimento urbano. Entende-se a grande heterogeneidade actual essencialmente como uma heterogeneidade de situações, que obriga a uma elasticidade disciplinar, e a desenvolver o conceito de cenários urbanos (Font. id.).

$\mathrm{Na}$ conjugação destes focos de abordagem, o exercício de taxonomização de formas reconhecíveis e classificáveis perante uma nova estrutura urbana cuja dispersão existe ao nível da própria percepção dos cidadãos, resulta, evidentemente, bem mais complexo, mas também bem mais cativante. O acima referido PROTAML procura ir neste sentido, projectando as suas estratégias territoriais por sete tipos de dinamismos espaciais: espaços motores, espaços problema, áreas críticas urbanas, espaços emergentes, áreas com potencialidades de reconversão/renovação, áreas dinâmicas periféricas, espaços naturais protegidos. Sem descurar esta interessante caracterização, cujo grande objectivo é programático, sugeriríamos um diferente olhar, cujas lentes valorizem de uma forma mais intersticial os comportamentos individuais, sociais e económicos, ao mesmo tempo não descurando os enquadramentos morfológicos (também eles sociais e económicos) que evidentemente também condicionam e fomentam diferentes tipos de dinâmicas - lentes especialmente relevantes na análise de elementos de forte cariz interdisciplinar e impacto cultural e identitário, como são os espaços públicos.

A classificação sugerida interliga por conseguinte as componentes de estrutura (procurando esta centrar dimensões chave na conjugação dos diferentes sentidos morfológicos, mas também dinâmicos), e dos cenários urbanos, subdividindo-os em termos dos processos presentes de evolução urbana.

${ }^{7}$ Resolução do Conselho de Ministros n. ${ }^{\circ}$ 68/2002 
Quadro n. ${ }^{\circ} 1$ - Componentes de Estrutura, Cenários Urbanos e Processos de Evolução Urbana

\begin{tabular}{|c|c|}
\hline Estrutura & Cenários Urbanos \\
\hline A. Tecidos compactos & 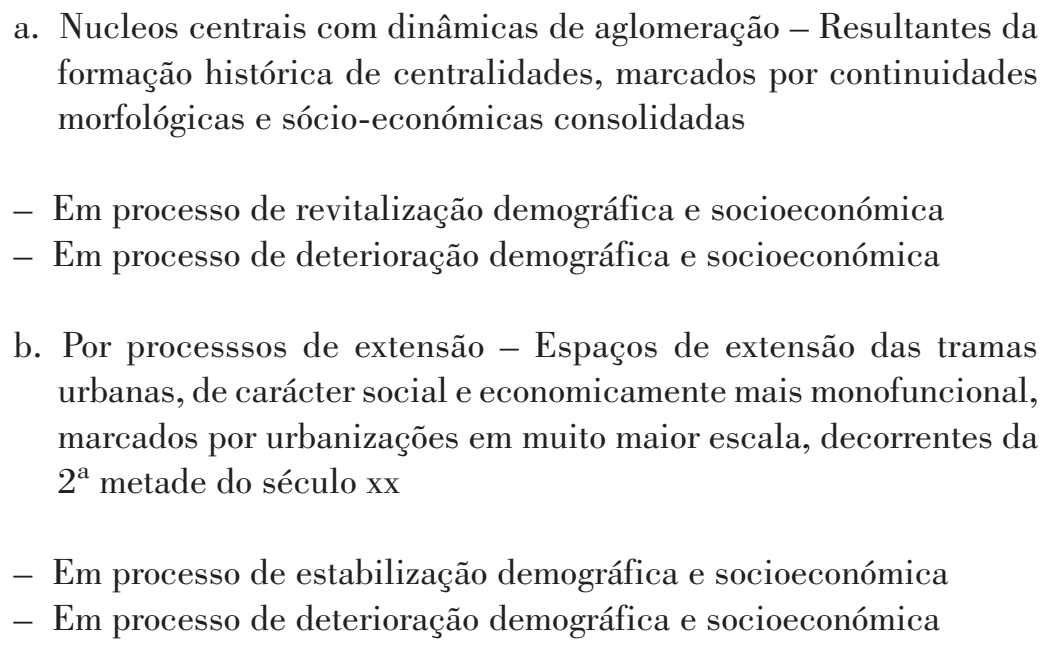 \\
\hline $\begin{array}{l}\text { B. Ambientes de baixas } \\
\text { densidades }\end{array}$ & $\begin{array}{l}\text { a. Espaços desagregados - Definindo lógicas de urbanização } \\
\text { descontínua e de carácter disperso, de índole essencialmente } \\
\text { habitacional, marcados por forte mobilidade individual } \\
\text { b. Dispersos - Ocupação rústica do território }\end{array}$ \\
\hline $\begin{array}{l}\text { C. Desenvolvimentos } \\
\text { multiplicadores }\end{array}$ & $\begin{array}{l}\text { a. Arteriais - Consolidação por extensões lineares, em artérias ou } \\
\text { canais de comunicação, por estas interligadas com os espaços de } \\
\text { centralidade } \\
\text { b. Pólos - Espaços de vitalidade por dinâmicas essencialmentes } \\
\text { económicas e de emprego } \\
\text { c. Territórios de rótula - Intervenções urbanas catalíticas, despertando } \\
\text { consolidações adjacentes }\end{array}$ \\
\hline D. Vazios urbanos & Espaços incertos e de marginalidade \\
\hline
\end{tabular}

Este exercício tipológico tratou-se de uma etapa fundamental da investigação que aqui se apresenta. De facto, a classificação dos territórios metropolitanos nestas quatro categorias permitiu apoiar o trabalho das morfologias sociais e urbanas, nomeadamente ao nível da delimitação das zonas no interior de cada concelho em análise. Mas também sustentar a selecção dos espaços privilegiados de observação.

\section{Das Morfologias Sociais e Urbanas}

Proceder a uma caracterização morfológica de alguns concelhos da metrópole de Lisboa, foi uma opção metodológica que procurava responder a algumas dificuldades que se colocaram no início da pesquisa para a concretização dos objectivos delineados. Concretamente a equipa de investigação questionava-se, por um lado, sobre a forma de dar conta da interdependência analítica entre escalas urbanas, quando se procura ler a "lógica global" em espaços concretos, dotados de uma diversidade socioespacial determinante. Por outro lado, tornava-se necessário encontrar as técnicas de pesquisa mais adequadas para abordar a diversidade espacial e temporal do património urbano e do espaço público.

Reconhecendo-se a importância de olhar para o território da metrópole com diferentes lentes analíticas - as escalas metropolitana, urbana e local 
- tornava-se imprescindível partir de uma escala mais global. Esta opção não visava apenas vir a fundamentar a selecção dos espaços urbanos de referência e dos espaços privilegiados de observação sobre os quais se desenvolveria uma análise local mais fina (cf. mais adiante). O outro objectivo, complementar com o anterior, prendia-se com o facto da escala urbana permitir uma avaliação relativamente dinâmica da produção patrimonial, dos espaços públicos e dos projectos de mudança territorial em algumas zonas da metrópole, ao mesmo tempo que tendia a lançar contributos para uma leitura articulada e prospectiva entre as diversas áreas de análise.

Pretendia-se, pois, com a caracterização morfológica de algumas áreas da metrópole de Lisboa identificar os elementos mais qualificadores e desqualificadores do território, no sentido de vir a caracterizar aquilo que pode ser a "imagem de marca" de Lisboa, ou seja, as suas potencialidades de afirmação, bem como os estrangulamentos sócio-urbanísticos que poderão interferir naquela afirmação metropolitana. Embora se tenha privilegiado a selecção de algumas unidades de análise que correspondiam à delimitação administrativa dos concelhos, opção que se prendeu com o acesso mais facilitado à informação documental, procurou-se contrariar a lógica de análise intraconcelhia, privilegiando-se as situações de fronteira, ou seja, explorando-se mais intensamente as "contiguidades e continuidades" (no sentido atribuído por autores como T. Barata Salgueiro, 1999, 2001) dos espaços concelhios.

Mas para concretizar os objectivos acima enunciados procedeu-se à sistematização das dimensões a privilegiar na análise das morfologias sociais e urbanas, nomeadamente as formas de ocupação do solo, o património, os espaços públicos, a estrutura verde, a rede de acessibilidades, os equipamentos e serviços, os grupos sociais em presença e as dinâmicas quotidianas. Nem sempre foi possível garantir a exaustividade na recolha de informação para estas dimensões quer por limitações de acesso à informação, quer pela sua inexistência ou desfasamento temporal ${ }^{8}$.
Partindo-se da hipótese que existem determinadas áreas emblemáticas das transformações sociais e territoriais e condicionantes da configuração metropolitana, foram, assim, seleccionados, numa primeira fase, como espaços urbanos de referência, os concelhos de Sintra, Oeiras, Loures e Lisboa na margem norte e Almada e Seixal na margem sul. A opção por estas unidades territoriais teve em conta um conjunto de critérios, tais como:

- Áreas com dinâmicas de transformação sócio-urbanísticas recentes e significativas, ou seja, com intervenções relevantes (programadas ou realizadas) em termos de impacte urbano;

- Áreas ilustrativas da dinâmica de produção e transformação urbana do todo metropolitano (sem que tal signifique uma total consolidação, considerando que são muitas vezes espaços intersticiais e limítrofes menos densos ou vazios, indicadores de dinâmicas urbanas e de processos de produção urbana) mas, também, áreas ilustrativas de configurações e dinâmicas locais;

- Áreas susceptíveis de fornecer material empírico para a análise do protagonismo urbano da metrópole de Lisboa, tomando como dimensão de análise o espaço público (considerado nas suas vertentes urbanística, política e sociocultural, como se verá mais adiante).

No interior de cada uma daquelas unidades territoriais procedeu-se à criação de zonas com base na análise da informação recolhida para cada uma das dimensões acima referidas e tendo como pano de fundo a tipologia acima apresentada. $\mathrm{O}$ objectivo era delimitar áreas que apresentassem uma relativa homogeneidade territorial e que se enquadrassem na tipologia acima apresentada. Se em alguns casos este agrupamento foi possível com base na junção de algumas freguesias (o concelho de Oeiras é um exemplo desta situação), noutros casos a delimitação das zonas teve mesmo de ultrapassar as fronteiras do concelho (Almada e Seixal registaram esta situação). A título ilustrativo, refira-se três zonas constituídas no concelho do Seixal que se prolongam para outros municípios. É o caso da zona da Siderurgia Nacional que se prolonga para o

\footnotetext{
${ }^{8}$ É de referir, no entanto, o contributo de uma publicação do INE (1999), coordenada por João Ferrão, que apresenta uma análise tipológica, assente em variáveis socioeconómicas e relativas à habitação, para a área metropolitana de Lisboa. Sendo a informação de base recolhida à escala da subsecção estatística permitiu uma leitura mais fina dos território em análise, embora não dispensando o cruzamento com outras fontes. Em alguns casos, deste cruzamento resultaram algumas incongruências dos dados, superadas pelo conhecimento empírico das áreas em observação.
} 
concelho do Barreiro com a mesma configuração, mas também da zona de Santa Marta de Corroios/ Ponta dos Corvos/Alto do Moinho que tem nítidas ligações com uma zona de Almada, por se tratar de uma área de alta densidade que se desenvolveu integrada no eixo de expansão urbana deste município. Por fim, refira-se a zona de Fernão Ferro que apresenta um mosaico socialmente diversificado que se estende, com a mesma configuração, para o concelho de Sesimbra.

Esta análise das morfologias sociais e urbanas em algumas áreas da metrópole de Lisboa permitiu corroborar a ideia de que os limites administrativos concelhios nem sempre traduzem a realidade sóciourbanística dos municípios. Pelo contrário, fragmentam-na e tornam, muitas vezes, ineficazes os instrumentos de planeamento municipal, pensados à escala concelhia, quando mesmo ali ao lado "moram" fenómenos semelhantes.

\section{Espaço Metropolitano, Espaço Urbano, Espaço Público}

Procuraremos no ponto que segue dar conta da formulação da matriz conceptual e metodológica que pretende elucidar a seguinte questão: "de que modo a operacionalização do conceito de espaço público enquanto objecto central de analise poderá contribuir para o aprofundamento do que sabemos acerca do protagonismo urbano na metrópole de Lisboa?". No contexto da investigação em curso, o espaço público é um dos vector analíticos para olhar a cidade. As suas potencialidades analíticas residem não apenas na análise do que é materializável mas, também, no seu carácter multidimensional. A multidimensionalidade dos espaços públicos enfatizada por diversos autores (Borja, 2000, Brandão, 2000, Toussaint et al, 2001) reside tanto no plano urbanístico, como nos planos sociocultural e político. Aceder a esta multidimensionalidade do espaço público e da cidade implica aprofundar cada um destes planos analíticos.

Dada a enorme diversidade de realidades que compõe o espaço público (e o sistema urbano) várias são as fontes de complexificação do seu estudo. À multiplicidade de elementos possíveis acres- centa-se a diversidade de combinações e interacções entre elementos, usualmente associáveis à sua dimensão locativa. Outro factor de complexificação da análise do espaço público, explorando os planos analíticos adoptados, corresponde à necessidade de identificar e articular diferentes métodos de recolha de informação.

Ao integrarmos os planos sociocultural e político, importa inquirir diferentes modos de apropriação do espaço público por parte dos cidadãos e, uma vez que, como refere Jordi Borja (2000), compreender o urbano significa também compreender os actores com e sem influência na cidade, importa inquirir os diferentes modos de produção / transformação urbana, também eles reveladores da perspectiva política de encarar o cidadão e de conceber o sentido do seu quotidiano. Nos planos político e sociocultural, a multidimensionalidade do espaço público é visível sobretudo a partir da observação dos modos de apropriação, sejam eles espontâneos ou induzidos, mais ou menos ligados à função e à força simbólica ou à legibilidade. Os planos sociocultural e político manifestam-se, ainda, nos modos de produção do espaço público e da cidade. Adoptar numa só leitura estes três planos da multidimensionalidade implica desenvolver uma nova síntese do urbano (Roncaylo, 1986) introduzindo no debate novos elementos e testando modos de inquirição usualmente deixadas à margem da análise do urbano. Para dar conta dos três planos analíticos adoptados partimos de uma matriz centrada em quatro dimensões de análise: dimensão contexto urbano, dimensão urbanística e arquitectónica, dimensão configuração funcional e dimensão apropriação / mobilidade.

\section{Percurso Metodológico para a Definição de uma Matriz de Análise}

Procurou-se, assim, estruturar um quadro metodológico que facilitasse a utilização e articulação do material empírico resultante da inquirição de espaços públicos concretos da metrópole de Lisboa, olhada através de diferentes lentes analíticas: a escala metropolitana, a escala urbana e a escala local. 
Figura n. ${ }^{\circ} 1$ - Percurso metodológico para a definição de uma matriz de análise

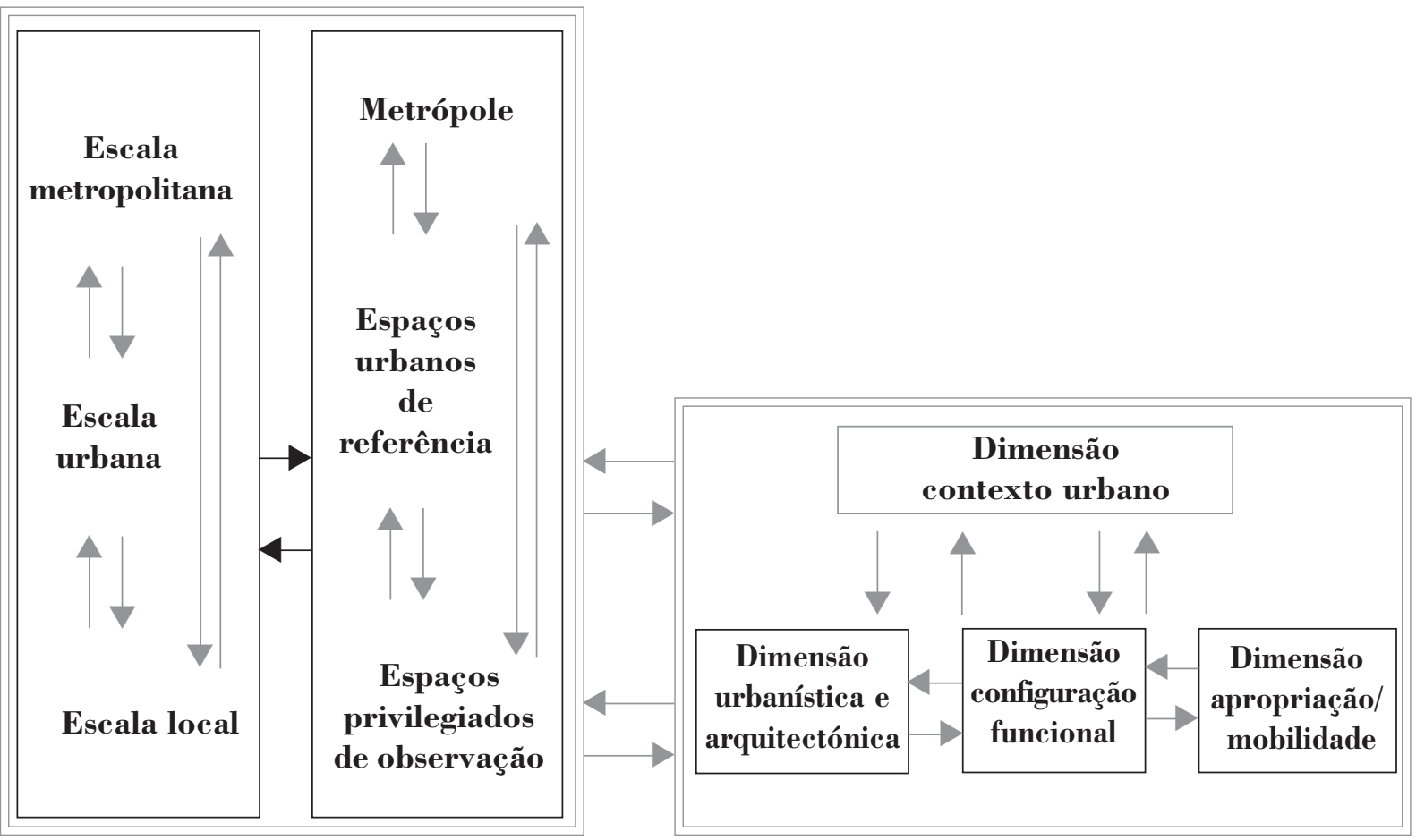

Para a estruturação das dimensões analíticas partimos da escala urbana, através da qual procuramos compreender outros espaços "territoriais" que permitem contemplar na análise elementos materializáveis, usualmente não contemplados no conhecimento do espaço público - e "conceptuais" - que inclui na análise dinâmicas de produção, transformação e de apropriação - dos espaços públicos a inquirir. As dimensões analíticas ${ }^{9}$ constituem-se, simultaneamente, como referências temáticas e metodológicas na abordagem do espaço público no contexto urbano da metrópole de Lisboa, e os seus significados podem diferir segundo a escala adoptada, isto é, segundo os espaços a que se reporta a análise e os actores presentes.

Conjugando três fontes de informação (entrevistas exploratórias, análise cartográfica e observação directa em locais específicos e utilizando percursos de automóvel e pedonais) considerámos ser possível definir com mais clareza os limites dos espaços urbanos de referência e identificar as componentes analíticas com relevância para a análise do protagonismo urbano em espaço público. A área piloto seleccionada para este estudo (Massamá e Barcarena) inscreve-se nos concelhos de Sintra e Oeiras. Tomando por referência a tipologia anteriormente apresentada, os espaços urbanos de referência seleccionados aproximam-se do tipo "tecido urbano compacto desenvolvido por processos de extensão e em processo de estabilização demográfica e sócioeconómica".

Para a área piloto desenvolvemos também uma análise mais pormenorizada de bases cartográficas. Confrontando cartas a diferentes escalas ${ }^{10}$ com a observação de ortofotomapas ${ }^{11}$ foi possível traçar parte do percurso evolutivo do processo de urbanização e consolidação urbana, aos quais se referenciariam, na nossa hipótese de trabalho, as questões a colocar em futuras entrevistas, e após observação directa. Complementarmente, procedeu-se ao levantamento de informação (referente aos processos de transformação urbana em curso e sobretudo no que concerne aos espaços públicos) junto das Câmaras Municipais.

A selecção dos espaços privilegiados de observação num espaço urbano de referência fez-se a partir da observação directa recorrendo a

\footnotetext{
9 Para a definição das dimensões analíticas procedemos à revisão e sistematização da informação já recolhida no âmbito das Morfologias realizadas e à revisão de alguns estudos realizados na AML (Morfologias Socio-económicas, INE, 1998; Barata Salgueiro (coord.), 1997, "Internacionalização, Reestruturação Económica e Produção de Novas Marginalidades na Região de Lisboa "; PROTAML )

10 À escala $1 / 10000$ e escala $1 / 5000$ datada de 1988 (posteriomente complementada com a escala $1 / 2000$ ampliada da mesma base).

11 A uma escala aproximada de $1 / 3000$ datados de 1995.
} 
percursos pedonais e de automóvel em diferentes momentos do dia. A partir destes percursos foi possível identificar diferentes tipos de espaços públicos, associados às funções residencial, comercial, de serviços e de circulação. O enquadramento urbano dos espaços privilegiados de observação foi complementado com a informação dos Censos de 91, tomando como referência a subsecção ${ }^{12}$. Para a área estudada, foi no entanto útil conhecer a priori a diversidade da densidade de ocupação, da estrutura etária dominante, entre outros aspectos, informação que se pretende confrontar a posteriori com os resultados obtidos a partir da observação directa. A análise do espaço público foi, assim, remetida para a escala local uma vez que só a mesma permite articular as dimensões urbanística e arquitetónica, configuração funcional e apropriação/mobilidade, como partes indissociáveis do todo urbano, lidando com diferentes temporalidades.

\section{Aproximação à Definição das Dimensões de Análise}

\section{Dimensão Contexto Urbano}

Conceptualizada ao nível das escalas urbana e local, a dimensão contexto urbano representa essencialmente uma análise interna da cidade reportada a espaços urbanos de referência, na perspectiva de Jordi Borja anteriormente referida. Nesta dimensão contempla-se a análise das condições de acessibilidade intra-metropolitana, atendendo aos elementos específicos da malha de acessibilidades, aos tipos de circulação dominantes e às características socioeconómicas da população. Para a recolha desta informação identificaram-se diferentes suportes: dados de mobilidade concelhia, cartas de hierarquia de vias, valores de fluxos de atravessamento por modos de transporte e informação dos Censos de 91 à escala da freguesia.

\section{Dimensão Urbanística e Arquitectónica}

Para estudar o espaço público na sua dimensão urbanística e arquitectónica, recorremos a diferentes conceitos com a preocupação de não cair num outro tipo de mancha urbana, correspondente ao esqueleto do antigo mosaico do zonamento urbano. Num território mal caracterizado no pormenor, o incremento da análise urbanística faz-se no sentido da visão micro mas, recusa-se o estudo de micro-espaços. Neste caso concreto, inseriu-se o espaço público no sistema urbano, visando conhecer, mais do que o espaço "rede de articulação", modos de articulação entre espaços públicos e entre estes e o edificado, com o qual interage, criando costuras, remates, barreiras. Trata-se de aferir a materialidade do espaço que constitui o primeiro nível de apropriação espacial e temporal. Esta dimensão - constituída por redes de ruas e avenidas, praças, espaços verdes e equipamentos -, usualmente entendida como a mais estável (porque composta por elementos tendencialmente mais permanentes), constitui a base a que se reportam as dimensões configuração funcional e apropriação/ mobilidade.

Para o desenvolvimento desta dimensão centramo-nos nas subdimensões analíticas de espaços públicos concretos: as estruturas edificadas e espaço não construído, tendo sido dentro deste último dada especial atenção às redes de suporte de deslocações, nomeadamente referenciando sinais formais de centralidade, observáveis a partir da largura das vias, ruas, avenidas, praças e das condições em que se processa a circulação.

\section{Dimensão Configuração Funcional}

Conceptualmente a análise da dimensão configuração funcional situa-se entre a análise da forma e da apropriação. Porque reportados a espaços concretos, não foi nossa preocupação proceder ao "clássico" levantamento funcional das actividades e equipamentos. Assim, apesar de ter sido possível identificar a localização de algumas funções urbanas a partir da análise da cartografia e ortofotomapas (especialmente no que se refere aos "espaços verdes", áreas de estacionamento, estações ferroviárias, entre outras), verificámos que é possível captar, recorrendo à observação directa, informação de base para o estudo da articulação entre espaços construídos e não construídos sem proceder à divisão axiomática - plano de cidade,

\footnotetext{
12 Apesar de desactualizados, estes dados permitem-nos uma aproximação à estrutura socioeconómica dos residentes das áreas contíguas aos espaços privilegiados de observação. Esta análise, apesar de oferecer alguma informação relevante para o enquadramento urbano destes espaços, encerra as debilidades típicas da informação indirecta, a que se acrescentam outros aspectos enviezadores, como uma cartografia por dominâncias percentuais, independentemente das densidades observadas, a desactualização temporal e as deficiências relativas à diversidade de situações urbanísticas que constituem a subsecção.
} 
funções, estilos arquitectónicos - tradicionalmente associada ao estudo da morfologia urbana (Clark, 1996: 5). Na verdade, e face aos objectivos da investigação, mais do que estabelecer hierarquias funcionais importa compreender as relações entre a função - dos equipamentos e as actividades económicas presentes - e os tipos de apropriação em espaços concretos. A observação de espaços concretos no que se refere à dimensão configuração funcional permitiu colocar como hipótese de trabalho a exploração do tipo de relação entre a diversidade de funções e os padrões de distribuição das mesmas e os modos de apropriação ao longo do tempo. Se por um lado, a observação das relações estabelecidas entre o tipo de função urbana e a respectiva apropriação indicia que nem sempre a segunda decorre da primeira, por outro, permite registar o potencial carácter estruturante que a função pode assumir. Deste modo a função pode entender-se como um "suporte materializável" (à semelhança da forma, embora teoricamente de modo menos estável) de estruturação do urbano pela via da apropriação espacial.

\section{Dimensão Apropriação/Mobilidade}

No confronto quotidiano com o espaço público o sujeito encontra oportunidades para desenvolver acções que tendem a alimentar a sua identidade pessoal, social e espacial. Estas acções, ou melhor, práticas de apropriação devem ser vistas como competências, capacidades dadas aos indivíduos no sentido de organizarem o espaço e para aí poderem inscrever a sua marca pessoal ou colectiva (Raymond, 1976: 76). Para H. Raymond a apropriação do espaço designa, assim, o conjunto de práticas que conferem a um espaço limitado as qualidades de um lugar pessoal ou colectivo: "Este conjunto de práticas permite identificar o lugar; este lugar permite engendrar práticas" (Raymond, 1976:76). A natureza da apropriação de um espaço público é à partida diferente daquela que se desenvolve nos espaços privados, daí que Raymond questione se não será um pouco aleatório a utilização de uma noção idêntica para realidades tão heterogéneas. A resposta parece estar no facto da apropriação dos espaços públicos derivar de práticas que neles se podem observar, mais do que expressões simbólicas destas práticas.
$\mathrm{O}$ estudo da dimensão apropriação/mobilidade associado à dimensão configuração funcional parece dar conta de um vasto e diverso conjunto de mobilidades e permanências, usualmente negligenciadas, que poderão constituir elementos relevantes para o objecto de investigação em curso. No entanto, a observação de diferentes intensidades e modos de apropriação sobre um mesmo espaço ao longo do dia, permite captar a "deslocação" de áreas centrais ${ }^{13}$ dentro do espaço urbano de referência não necessariamente ligadas a rotinas diárias associáveis, por exemplo aos horários de abertura de escolas ou lojas, às regras de controle de tráfego ou a itinerários, como sugere Allen (1999 cit. por Amin e Thrift, 2002: 19).

Nesta fase exploratória do trabalho, o nosso objectivo foi o de observar, igualmente, a intensidade e o tipo de práticas de sociabilidade em espaços privilegiados de observação específicos. Na medida em que a apropriação gera deslocações que estruturam a mobilidade espacial dos indivíduos, a análise local sugere e permite a agregação destas duas componentes analíticas. Esta dimensão é central uma vez que permite identificar espaços aglutinadores de fluxos e/ou que constituem suportes de práticas de apropriação mais ou menos cristalizadas. Nesta dimensão apostamos na dimensão/variável tempo, aproximando-nos daquilo que Lefebvre (1996, cit. por Amin e Thrift, 2002: 16-17) designa por "ritmos", tentando perceber o pulsar da cidade e a partir daí conhecer e tipificar os espaços públicos que suportam e veiculam formas de protagonismo. Para além do desenho dos espaços públicos, tornase necessário uma observação dos seus traços de ocupação quotidiana, pois as relações entre a esfera pública e a privada tornam-se cada vez mais complexas, fruto de serem reguladas por formas diferenciadas em função dos contextos sociais.

De acordo com as dimensões analíticas anteriormente expostas, o quadro seguinte sistematiza as componentes de análise equacionadas para avaliar o protagonismo urbano em espaço público. Tais componentes foram testadas pela observação directa em espaços públicos concretos na área piloto seleccionada, excepto no caso da dimensão contexto urbano, como adiante se explicitará.

\footnotetext{
${ }^{13}$ As áreas centrais são aqui entendidas como espaços onde se observam maiores intensidades de apropriação.
} 
Quadro n. ${ }^{\circ} 2$ - Componentes e Dimensões de Análise

\begin{tabular}{|c|c|}
\hline Dimensões & Componentes Analíticas \\
\hline Contexto Urbano & $\begin{array}{l}\text { - Tecido urbano - tipo de planta presente, níveis de densidade, estrutura/di- } \\
\text { mensão do espaço aberto face ao edificado, presença de vazios urbanos } \\
\text { contíguos, pressão construtiva na envolvente, eixos/nós de estruturação } \\
\text { - Malha de acessibilidade física externa - articulação com a rede de circulação } \\
\text { de escala metropolitana } \\
\text { - Malha de acessibilidade física interna - rede de transportes e pedonal } \\
\text { - Características socioeconómicas dos residentes - estrutura etária, profissional } \\
\text { e mobilidade residencial } \\
\text { - Usos dominantes - padrão de localização, tipo e peso dos usos residencial e } \\
\text { não residencial } \\
\text { - Mobilidade da população - mobilidade por tipos de transportes }\end{array}$ \\
\hline $\begin{array}{c}\text { Urbanística } \\
e \\
\text { Arquitectónica }\end{array}$ & $\begin{array}{l}\text { Subdimensão Edificado } \\
\text { - Volume do edificado / densidade da edificação } \\
\text { - Tipo de agrupamento dos edifícios } \\
\text { - Média de idade dos edifícios } \\
\text { - Estado de conservação do edificado } \\
\text { - Valor monumental do edificado, valor singular e de conjunto } \\
\text { - Intervenções no edificado - renovação, reabilitação, requalificação } \\
\text { - Tipos de acesso - físico e socioeconómico } \\
\text { Subdimensão Espaço Público } \\
\text { - Área descoberta destinada a espaço público } \\
\text { - Malha de distribuição do espaço público por tipos de uso dominantes } \\
\text { - Barreiras físicas e simbólicas } \\
\text { - Equipamentos existentes } \\
\text { - Estado de conservação e manutenção } \\
\text { - Valor monumental do espaço público (expresso pelo valor monumental dos } \\
\text { seus elementos) } \\
\text { - Tipos e intensidade de sons e cheiros } \\
\text { - Valor urbano (qualidade da expressão formal, qualidade do património, } \\
\quad \text { expressividade do conjunto, singularidade - elementos distintivos) } \\
\text { - Configuração Funcional } \\
\text { - Tipo de equipamentos colectivos - permanentes e móveis - quanto ao serviço } \\
\text { prestado, intensidade de uso e tipo e densidade de utilizadores }\end{array}$ \\
\hline $\begin{array}{l}\text { Configuração } \\
\text { Funcional }\end{array}$ & $\begin{array}{l}\text { - Tipo de equipamentos colectivos - permanentes e móveis - quanto ao serviço } \\
\text { prestado, intensidade de uso e tipo e densidade de utilizadores } \\
\text { - Tipo de actividades económicas - permanentes e móveis - quanto ao serviço } \\
\text { prestado, intensidade de uso e tipo e densidade de utilizadores } \\
\text { - Acessibilidade física e socioeconómica } \\
\text { Estatuto (valor patrimonial dos edifícios / equipamento ou actividade presente) } \\
\text { - Características do emprego (nível de qualificação e de rotatividade, horários } \\
\text { de trabalho) } \\
\text { - Níveis de adesão entre actividades presentes } \\
\text { - Relações entre actividades e espaço público }\end{array}$ \\
\hline $\begin{array}{c}\text { Apropriação / } \\
\text { mobilidade }\end{array}$ & $\begin{array}{l}\text { - Tipos de práticas induzidas e não induzidas (desporto, jogos, namoro, } \\
\text { consumo, contemplação, encontro, prostituição...) } \\
\text { - Nível de adesão ao uso formalmente definido } \\
\text { - Práticas colectivas e individuais (tipo de utilizadores, grupos estáveis e } \\
\text { efémeros quanto à estrutura etária, identificação cultura e étnica) } \\
\text { - Ritmos de uso (temporalidade, rotatividade) } \\
\text { - Tipos de circulação (fluxos internos e de atravessamento) } \\
\text { - Impacto do automóvel na circulação pedonal e na apropriação }\end{array}$ \\
\hline
\end{tabular}


Numa primeira aproximação, como se depreende da exposição do percurso metodológico, incluímos na análise os aspectos relativos às dinâmicas de produção, consolidação e transformação urbanística, assim como as dinâmicas de apropriação socio-espacial procurando construir uma única matriz analítica de registo de todos os elementos considerados relevantes para o objectivo da investigação, independentemente dos métodos de recolha de informação. A matriz anlítica de partida sistematiza assim, um conjunto de componentes analíticas inscritas nas dimensões de análise propostas e constitui a base de uma grelha de análise que, na sua primeira versão, se pretendeu preencher a partir do cruzamento de fontes de informação distintas.

Para a realização do trabalho de campo (assente na observação directa) em espaços públicos concretos, foram eliminadas, da grelha acima referida, as componentes não legíveis a partir daquela metodologia ${ }^{14}$. Contudo, optou-se por manter algumas componentes - de que são exemplo a componente características do emprego (nível de qualificação e de rotatividade, horários de trabalho); níveis de adesão entre actividades presentes e relações entre actividades e espaço público - que podem ser parciamente aferidas a partir da observação directa. Por outro lado, incluiram-se outras componentes que decorrem da articulação entre os resultados empíricos da observação de componentes directamente observáveis como é o caso, por exemplo, do valor urbano que constitui uma síntese da qualidade da expressão formal, qualidade do património, expressividade do conjunto, singularidade elementos distintivos.

Partindo da grelha de componentes expostas e que resultou do processo de triagem acima referido, procedeu-se a um pré-teste realizado em espaços privilegiados de observação (tomando como referência o espaço público e as estruturas edificadas que o definem) com os objectivos de compreender as relações estabelecidas entre as diferentes dimensões em análise, e de avaliar a adequabilidade daquela grelha analítica para a metodologia de recolha de informação (a observação directa) também ela em teste. Assim, a observação directa constituiu o primeiro passo para testar a pertinência teórico-conceptual das dimensões e componentes analíticas propostas.

\section{Notas de Remate ou da Necessidade de Continuar a Investigação}

Como contributo da observação directa para a investigação em curso saliente-se a identificação de diferentes níveis de subjectividade do material empírico recolhido. De facto, ao procurarmos identificar elementos qualificadores e desqualificadores do espaço público enquanto suporte e manifestação de protagonismo urbano, mesmo isolando sob a forma de componentes analíticas os critérios em jogo, torna-se necessário concretizar um conjunto de conceitos que não são de fácil objectivação, entre os quais se destacam conceitos como barreiras, rupturas, continuidade, descontinuidade.

No entanto, refira-se que, face ao trabalho desenvolvido, apenas foi possível proceder à afinação da grelha em análise no que se refere à representatividade temática das componentes seleccionadas, mantendo-se por validar a sua possível (e não pacífica) estabilização após o confronto entre realidades socioespaciais distintas. $\mathrm{Na}$ verdade, neste processo de afinação foi possível verificar que a impossibilidade de caracterização de espaços concretos no que se refere, a determinadas componentes pode ter diversas explicações. Uma delas pode ser associada à natureza desses mesmos espaços, a outra pode prender-se com as limitações que a observação directa levanta, necessitando por isso de ser conjugada com outras técnicas de recolha de informação. Neste processo de progressiva afinação por eliminação, adição ou reestruturação de componentes analíticas, o confronto entre espaços metropolitanos distintos parece ser incontornável e dele se esperam contributos que permitam testar a aplicabilidade do instrumento analítico em construção a outros contextos.

A natureza do material empírico, resultante de cada uma das lentes analíticas utilizadas, não é absolutamente comparável e transponível. Por

\footnotetext{
${ }^{14}$ A investigação em curso contempla a elaboração e teste de outras metodologias e instrumentos de recolha de informação para além da grelha aplicada a espaços públicos concretos definidos como espaços privilegados de observação. Tomando como referência as dimensões em análise ponderou-se a hipótese de identificar um quadro de actores a inquirir com o objectivo de complementar e confrontar o material empírico resultante da aplicação de entrevistas com os resultados da análise de espaços urbanos de referência e da observação directa espaços privilegiados de observação.
} 
este motivo, apesar de assente numa estrutura vertical o estudo do local não é, na nossa abordagem, um zoom do urbano e metropolitano, uma vez que, como já referimos, os conceitos centrais da análise empírica adquirem novos significados. Deste modo, a dimensão contexto urbano surge como uma plataforma entre o local e metropolitano, mas não se reduz ao enquadramento dos primeiros e pormenorização dos segundos.

A operacionalização do conceito de espaço público, considerando os planos urbanístico, sociocultural e político, resultou de um exercício de sucessivas reformulações da matriz de análise, que culminou na construção de uma grelha analítica que integra componentes de análise do espaço urbano de referência e componentes de análise dos espaços privilegiados de observação.

O carácter compósito e dinâmico de algumas componentes e a relutância em adoptar esquemas prévios de categorização levou a que se admitisse que certas componentes de análise se possam inscrever em mais do que uma dimensão analítica, em virtude de termos optado, numa primeira fase, pela construção de uma matriz de análise comum a duas lentes analíticas: a local e a urbana. Esta opção foi ainda considerada uma forma eficaz de balizar a subjectividade inerente à aplicação dos métodos de recolha de informação de carácter subjectivo a desenvolver na análise local.

Esta opção decorre também de condicionantes impostas pela natureza da informação disponível. Por exemplo: depois de definidas as espaços urbanos de referência procurou-se saber mais sobre os respectivos espaços públicos, questionando as Câmaras Municipais sobre os mesmos. A informação obtida na maior parte dos casos coincide geograficamente com o concelho e / ou ao aglomerado ou freguesia. Torna-se assim necessário manter algumas componentes de análise (áreas, funções, intervenções recentes, e outros indicadores apenas aferíveis pela observação) na grelha a preencher pela observação directa destes espaços e/ou da inquirição de actores. Deste modo, procurou-se por um lado, colmatar lacunas de informação existen- tes e, por outro, quando possível, garantir a possibilidade de confrontar informação decorrente da aplicação de diferentes metodologias.

Partindo das quatro dimensões analíticas propostas procura-se uma nova síntese do urbano na qual o espaço público é simultaneamente objecto de análise - que se reporta a diferentes espaços privilegiados de observação que se inscrevem no espaço e no tempo em determinadas espaços urbanos de referência - e vertente analítica privilegiada para a concretização dos planos analíticos que enquadram o estudo do protagonismo urbano em espaço público. Trata-se assim de um objecto de estudo materialmente concretizado e conceptualmente alargado.

A matriz analítica centrada no espaço público enquanto base para o estudo do protagonismo urbano (nas perspectivas urbanística, política e sociocultural) requer o recurso a um conjunto de metodologias diversificadas ${ }^{15}$. Este percurso reveste-se de especial interesse, não apenas pelas possibilidades que tal cruzamento oferece na colmatação de lacunas de informação, mas também, e sobretudo, pelas possibilidades analíticas decorrentes da confrontação de diferentes modos de viver e interpretar um mesmo objecto urbano: o espaço público.

Este é dos maiores contributos que o estudo do espaço público poderá trazer à análise da cidade, e um dos fundamentos da linha metodológica seguida, que procura articular escalas e dimensões de análise da cidade, para conhecer o objecto de análise central desta investigação: o espaço público nos seus planos urbanístico, sociocultural e político.

Porque se trata de um estudo exploratório, o seu aprofundamento permitirá testar a "representatividade geográfica" dos espaços seleccionados para estudo e a "representatividade temática" das dimensões do espaço público em análise para a problemática em estudo. A grelha permite testar o que Clark (1996: 19 e 323) designa de relevância prática e académica dos estudos desta natureza.

\footnotetext{
${ }^{15}$ A título de exemplo, o pré-teste da grelha analítica e concretamente no que se refere à apropriação mostra que a observação directa é por si só limitada enquanto metodologia para a identificação do tipo de práticas quando não sistemática no tempo.
} 


\section{Bibliografia}

AMEndolA, G., 2000, La Città Postmoderna, Roma-Bari, Ed. Laterza.

AMIN, A., THRIFT, N., 2002, Cities. Reimagining the urban, Cambridge, Polity Press.

BARATA SALGUEIRO, T., 1999, "Cidade pósmoderna. Espaço fragmentado", in $3^{\circ}$ Congresso de Geografia Portuguesa, Porto, Ed. Colibri e Associação Portuguesa de Geógrafos, pp. 225-236.

BARATA SALGUEIRO, T., 2001, Lisboa, periferia e centralidades, Oeiras, Celta.

BORJA, J., 2000,"Fazer cidade na cidade actual. Centros e espaços públicos como oportunidades" in BRANDÃO, P.; REMESAR, A. (coord.) Espaço Público e Interdisciplinaridade, Lisboa, Centro Português do Design.

BRANDÃO, P.; REMESAR, A. (coord.), 2000, Espaço Público e Interdisciplinaridade, Lisboa, Centro Português do Design.

CASTro, A., 2002, "Espaços Públicos, Coexistência Social e Civilidade. Contributos para uma Reflexão sobre os Espaços Públicos Urbano, Cidades. Comunidades e Territórios n ${ }^{\circ}$ 5, pp. 53-67.

CHOAY, F., 1996, L'Allégorie du Patrimoine, Paris, Ed. du Seuil.

CLARK, D., 1996, Urban World. Global City, Routledge, London.

COSTA, A. F., 1999, Sociedade de Bairro. Dinâmicas Sociais da Identidade Cultural, Lisboa, Celta Ed.

FERREIRA, V. M. et al., 1997, Lisboa, a Metrópole e o Rio, Lisboa, Ed. Bizâncio.

FERREIRA, V. M., 2000, "Cidade e Democracia", Cidades. Comunidades e Territórios, 1, pp. 9-35.
FERREIRA, V. M., 2001, "Protagonismo Urbano e Projecto de Cidade", Cidades. Comunidades e Territórios, 2, pp. 33-45.

FONT, A, 1999, La Construcción del Territori Metropolitá. Morfogénesis de la Régio Urbana de Barcelona, Ed. Mancomunitat de Municipis de L’Àrea Metropolitana de Barcelona.

FORTUNA, C., 1999, Identidades, Percursos, Paisagens Naturais, Oeiras, Celta.

INE,1999, Tipologia Sócio-Económica da Área Metropolitana de Lisboa, INE/AML, Lisboa.

MEPAT, 1999, Plano Nacional de Desenvolvimento Económico e Social 2000-2006, Lisboa, Ministério do Equipamento, do Planeamento e da Administração do Território.

NEL.LO, O., 2001, Ciutat de Ciutats, Barcelona, Editorial Empúries.

RAYMOND, Henri, 1976, "Quelques aspects theoriques et pratiques de l' appropriation de l'espace" in KOROSEC SERFATY (ed.), Apropriation de l'espace, Actes de la confèrence de Strasbourg, Louvain - la - Neuve.

RIBEIRO, J. F., 1998 “O Plano Nacional de Desenvolvimento Económico e Social (PNDES). Implicações para o ordenamento do território - uma leitura" in MEPAT, O território para o século XXI, Seminário Internacional, Lisboa, Ministério do Equipamento, do Planeamento e da Administração do Território.

RONCAYLO, M., 1986, "Cidade" in Enciclopédia Einaudi, Volume 8, INCM.

SECCHI, B, 1995, "Resoconto di una Ricerca", Urbanistica n. ${ }^{\circ}$ 103, Barcelona. 